\title{
Cuidados Paliativos no Reino Unido: A Minha Experiência em Manchester
}

\section{Palliative Care in the United Kingdom: My Experience in Manchester}

\author{
André COCHOFEL ${ }^{1}$, Ana CARDOSO ${ }^{2}$, Michael TAPLEY² \\ Acta Med Port 2018 Mar;31(3):144-145 - https://doi.org/10.20344/amp.9497
}

Palavras-chave: Continuidade de Cuidados ao Doente; Cuidados Paliativos em Final de Vida; Cuidados Terminais; Hospitais para Doentes Terminais; Portugal; Reino Unido

Keywords: Continuity of Patient Care; Hospice Care; Hospices; Palliative Care; Portugal; United Kingdom

Mrs. Smith morria. Fora acolhida no hospice (N. do A.: o autor mantém a palavra hospice que em Inglês se refere a um centro especializado em cuidados paliativos para evitar equívoco com o termo Hospício que em português se refere a um centro de cuidados psiquiátricos) por um carcinoma do endométrio com metastização óssea, encontrando-se dispneica e com uma tosse produtiva de cor esverdeada. À auscultação apresentava fervores generalizados bibasais.

$\mathrm{Na}$ discussão diária com a equipa multidisciplinar do Hospice (constituída por médicos, enfermeiros, assistentes sociais, fisioterapeutas, assistentes operacionais, counsellors, terapeutas de medicina complementar e estudantes de medicina e enfermagem), concluiu-se que se tratava de uma pneumonia, decidindo-se iniciar octreótido e morfina numa bomba infusora. Ao questionar se se deveria iniciar antibioterapia, as palavras do Dr. Michael Tapley, diretor do hospice, ressoaram em mim: "Esta doente vai morrer nos próximos dias, achas que quer iniciar mais um medicamento?"

Efetivamente, ao questionar a Mrs. Smith, descobri que a mesma se encontrava exausta dos tratamentos e pretendia apenas morrer sem dor, o que sucedeu após uns dias quando faleceu rodeada de familiares e amigos.

Nunca a importância da medicina centrada no paciente me fizera tanto sentido como naquele momento.

\section{Contexto dos cuidados paliativos no Reino Unido}

A origem dos cuidados paliativos no Reino Unido remonta aos anos $60 \mathrm{com}$ a formação do primeiro hospice em 1967 por Dame Cicely Saunders. Durante estes quase 50 anos de experiência, os cuidados paliativos no Reino Unido transformaram-se numa prática insubstituível para a população local, cuja acessibilidade é uma mais-valia cada vez mais reconhecida a nível nacional e internacional. ${ }^{1}$

$\mathrm{O}$ meu interesse nesta área surgiu durante o Ano Comum, onde diversos casos domiciliários e hospitalares me fizeram ponderar a importância da criação de redes de cuidados paliativos mais integrados e céleres para os doentes terminais. Não eram incomuns os casos de doentes que esperavam ser integrados num serviço de cuidados paliativos, acabando por falecer em casa ou numa cama hospitalar, sem qualquer dignidade.

Quando em agosto de 2016, durante o meu segundo ano de internato de medicina geral e familiar, surgiu a oportunidade de realizar um estágio em Cuidados Paliativos no Reino Unido, segui esse objetivo de modo a familiarizar-me com realidades e sistemas de saúde distintas, com a finalidade de partilhar essa experiência com outros profissionais de saúde em Portugal.

Através de uma amiga que realizara um estágio no Willow Wood Hospice, em Ashton-under-Lyne, uma pequena cidade situada perto de Manchester, entrei em contacto com o mesmo hospice e procedi à organização dos documentos e estadia necessários.

\section{O Hospice}

Os hospices são estabelecimentos financiados por diversas instituições de solidariedade social a nível local, que prestam cuidados a doentes terminais e com doenças crónicas complexas. ${ }^{1}$ O Willow Wood Hospice, em particular, é um estabelecimento constituído por um grupo de 14 médicos e 30 enfermeiros, com interesses comuns na área dos cuidados paliativos. O número de doentes que recorre ao Hospice no espaço de um mês é de cerca de 100. Este rácio de profissionais de saúde/doentes permite a individualização de cada caso e a centralização no doente como agente decisivo do seu tratamento. ${ }^{2}$

A minha primeira impressão do Hospice foi o seu luminoso interior e a limpeza dos seus quartos, arejados e cheirosos. Imediatamente o contraste com muitos serviços hospitalares e até mesmo lares em Portugal se fez notar. Durante uma visita guiada pelas instalações e os jardins verdejantes, o Dr. Tapley argumentava sobre a importância de fornecer aos doentes o conforto necessário, referindo que muitos doentes optavam por morrer rodeados pela natureza, ouvindo o som dos pássaros e da água da fonte. Esta imagem marcou-me particularmente.

A abertura e simpatia dos membros do Hospice para

1. Unidade de Saúde Familiar Flor de Lótus. Cacém. Portugal.

2. Willow Wood Hospice. Ashton-under-Lyne. Manchester. United Kingdom.

$\triangle$ Autor correspondente: André Cochofel. andre.cochofel@gmail.com

Recebido: 28 de julho de 2017 - Aceite: 25 de outubro de 2017 | Copyright @ $\odot$ Ordem dos Médicos 2018 
comigo foi notável. Desde o primeiro dia que me senti ativamente enquadrado no serviço, participando nas reuniões de serviço, onde o meu feedback sobre os casos clínicos era ouvido e estimulado.

Ainda que o clima na Inglaterra se apresentasse frequentemente chuvoso e cinzento, sentia uma energia positiva permanente e uma sensação de propósito no Hospice, apesar da proximidade constante com a morte.

O tema de fim-de-vida é abordado no Hospice de uma forma aberta e autêntica. Ao invés de abordar o fim de terapêutica como um tabu, como frequentemente acontece em Portugal, os doentes são questionados ativamente sobre a cessação da terapêutica, o que, para minha surpresa inicial, a vasta maioria dos doentes acaba por consentir.

No final do meu estágio foi-me pedida uma apresentação sobre a diferença de decisões éticas no contexto clínico em Portugal e no Reino Unido, para expor no hospital local de Tameside. A descoberta de vários artigos sobre as diferenças entre ética mediterrânica e anglo-saxónica possibilitou-me explorar diferentes filosofias e modos de pensar, permitindo integrar o contexto dos cuidados paliativos diretamente ao nível geográfico.

\section{Cuidados Paliativos: Reino Unido versus Portugal}

Na minha opinião, existe uma grande disparidade entre Portugal e o Reino Unido no que diz respeito aos cuidados paliativos.

O primeiro centro de cuidados paliativos em Portugal foi criado em 1992 no Fundão, tendo o Programa Nacional de Cuidados Paliativos sido estabelecido apenas em 2004. Em 2006 foi formada a Rede Nacional de Cuidados Continuados Integrados, que se viria a tornar no principal sistema de referenciação de doentes para os Cuidados Paliativos. Neste momento a Rede é demasiado rígida, burocrática e lenta para dar resposta às necessidades populacionais dos portugueses - não por falência dos profissionais nem das equipas coordenadoras locais e regionais, mas pelo formato do próprio sistema. ${ }^{3}$

\section{REFERÊNCIAS}

1. About Paliative Care. London: Cicely Saunders International; 2017; [Consultado 2017 Mai 19]. Disponível em: http:// cicelysaundersfoundation.org/about-palliative-care.

2. Willow Wood Hospice. Ashton-under-Lyne: Willow Wood Hospice; 2017; [Consultado 2017 Mai 19]. Disponível em: http://www.willowwood.info/.

3. Marques AL, Gonçalves E, Salazar H, Neto IG, Capelas ML, Tavares M, et al. O desenvolvimento dos cuidados paliativos em Portugal. Pat Care.
O que observei no Reino Unido foi um processo célere. Qualquer profissional de saúde pode referenciar diretamente o doente, através de um simples telefonema ou preenchimento de um formulário. Na vasta maioria dos casos, os doentes são referenciados em horas em vez de semanas e a primeira observação no hospice é feita no próprio dia da referenciação.

Torna-se ainda importante refletir sobre a pouca atenção que a área dos cuidados paliativos merece nos cursos de medicina e enfermagem em Portugal. No Reino Unido, os cuidados paliativos fazem parte integrante dos currículos universitários e qualquer profissional de saúde pode enveredar por este caminho, caso tenha interesse na área. Em Portugal, a unidade curricular de Cuidados Paliativos tornou-se pela primeira vez obrigatória em 2016 para o curso de medicina na Universidade de Lisboa, sob a coordenação do Prof. Doutor António Barbosa, colmatando uma grande lacuna na educação médica portuguesa.

\section{Modelo de Cuidados Paliativos inglês - um modelo a adoptar?}

Ainda que o sistema de Cuidados Paliativos no Reino Unido tenha por base um modelo holístico, com um processo de referenciação rápida, entendo que são as características intrínsecas do próprio país que o permitem. A experiência acumulada nesta área no Reino Unido permitiu uma aceitação mais precoce dos Cuidados Paliativos por parte da população, a qual espera uma boa qualidade de morte no término da sua vida. ${ }^{4}$

Creio que em Portugal existe ainda um longo caminho a percorrer, que passará não só pela revisão do sistema com mais acessibilidade para a população, como ainda por uma mudança do paradigma de fim de vida por parte dos portugueses.

O modelo inglês poderá vir a ser seguido para melhorar vários aspetos da nossa realidade, nomeadamente no acesso célere a cada caso e na centralização no doente no momento da tomada de decisões.

2009;32-8.

4. Suresh T. The Quality of Death Index 2015 - Ranking palliative care across the world: A report by The Economist Intelligence Unit. London: Lien Foundation; 2015. [Consultado 2017 Mai 19]. Disponível em: http:// www.eiuperspectives.economist.com/healthcare/2015-quality-deathindex. 